\title{
ANALISIS TEKNO-EKONOMI SISTEM BACKUP DAYA PADA BASE STATION TRANCEIVER
}

\author{
Edwar $^{1}$ \\ ${ }^{1}$ Prodi Teknik Elektro FT UNPAM \\ Jln. Puspiptek Raya No 11 Buaran, Tangerang Selatan 15310 INDONESIA \\ dosen00575@unpam.ac.id
}

\begin{abstract}
ABSTRAK
Base Station Transceiver merupakan sub-sistem yang bertugas untuk melayani trafik pengguna pada sistem komunikasi selular. Lokasi Base Station Transceiver yang tersebar membuat sub-sistem tersebut tidak selalu mendapatkan catuan utama dengan tingkat availability yang baik (khususnya pada area bad grid), sehingga menyebabkan terjadinya traffic loss. Untuk mencegah hal tersebut diperlukan sistem backup daya pada Base Station Transceiver tersebut. Pada penelitian ini dilakukan analisis berbasis tekno-ekonomi dalam melakukan desain sistem backup daya pada Base Station Transceiver. Melalui beberapa parameter asumsi yang digunakan, hasil penelitian menunjukan bahwa parameter outage profile pada area bad grid dan potensi traffic loss prevention sangat berpengaruh dalam evaluasi feasibility. Dari rangkaian penelitian ini disimpulkan bahwa desain backup daya berbasis tekno-ekonomi dapat diterapkan sebagai model desain yang dapat memberikan evaluasi optimal baik secara teknis maupun aspek ekonomi.
\end{abstract}

Kata kunci : Tekno-Ekonomi, Backup Daya

\begin{abstract}
Base Station Transceiver is a sub-system that has function to serve user traffic flow on mobile communication system. The scattered location of the Base Station Transceiver makes this sub-system not always gets main power supply in adequate availability to operate (especially in bad grid areas), thus it lead to resulting of traffic loss. To prevent this issue we required power backup system for the Base Station Transceiver. According to this issue, we present the techno-economy based analysis in designing power backup system for Base Station Transceiver. Under several parameter assumptions used, the results showed that the outage profile parameter in the bad grid area and potential traffic loss prevention parameter are very influential for feasibility evaluation. From this research we can conclude that techno-economic powered backup design can be applied as a design model that can provide optimal evaluation both technically and economically.
\end{abstract}

Keywords : Techno-Economic, Power Backup System

\section{PENDAHULUAN}

$\mathrm{D}$ alam sistem komunikasi selular, Base Station Transceiver merupakan bagian sub-sistem yang secara langsung berinteraksi dengan pengguna selular sehingga menjadi gerbang terdepan dalam menangani aliran trafik dari pengguna selular.

Lokasi Base Station Transceiver yang tersebar ke berbagai wilayah menyebabkan sub-sistem tersebut tidak selalu mendapatkan catuan daya utama dengan tingkat availability yang baik (khususnya pada area bad grid yang mengalami 
pemadaman bergilir hingga berjam-jam), sehingga menyebabkan terjadinya traffic loss bagi operator telekomunikasi.

Kajian terkait analisa tekno-ekonomi dalam bidang energy storage terdapat dalam literatur [11] dan [12] namun dalam penelitian tersebut tidak berfokus pada sistem backup daya untuk infrastruktur telekomunikasi selular. Dalam literature [2], [3], dan [4] analisa tekno-ekonomi diterapkan dalam dimensioning infrastruktur telekomunikasi namun tidak berfokus kepada sistem backup dayanya.

Untuk hal tersebut maka dalam penelitian ini dikembangkan analisa sistem backup daya berbasis tekno-ekonomi pada Base Station Transceiver yang terletak pada area catuan bad grid, dimana dalam melakukan desain sistem backup daya pada Base Station Transceiver tersebut dimensioning teknis akan diselaraskan dengan aspek ekonomi sehingga dihasilkan desain yang optimal baik secara teknis maupun aspek ekonomi.

\section{TEORI}

Secara umum skema aliran catu daya Base Station Transceiver dapat diilustrasikan seperti pada Gambar 1, dimana catuan utama pada Base Station transceiver tersebut menggunakan catuan dari PLN (power grid).

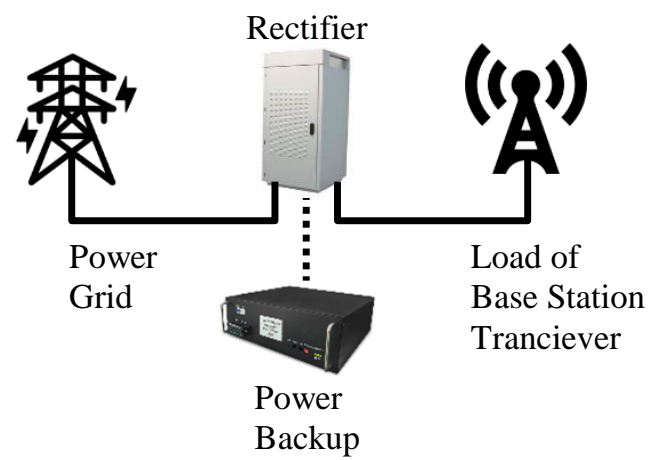

Gambar 1. Skema Dasar Sistem Catuan Utama dan Backup Daya Pada Base Station Tranciever

Namun dalam hal kondisi kekurangan daya, maka terdapat area-area power grid yang mengalami pemadaman secara regular hingga berjam-jam, untuk itu maka diperlukan sistem backup daya bagi Base Station Transceiver agar tetap dapat menampung aliran trafik dari pengguna selular.

Terdapat dua komponen utama dalam desian sistem backup daya pada Base Station Tranceiver, yang pertama adalah kapasistas batre, dan yang kedua adalah kapasitas rectifier. Kapasitas batre yang harus disediakan adalah berbanding lurus dengan besarnya arus dan lamanya durasi backup yang diperlukan, sehingga dapat disimplifikasikan dengan formula berikut [11],

$$
B_{\text {capacity }}=\frac{L}{v} \times t_{d} \times \frac{1}{\eta}
$$

dimana,

$$
\begin{array}{ll}
\boldsymbol{B}_{\text {capacity }} & =\text { Kapasitas Backup (Ah) } \\
\boldsymbol{L} & =\text { Beban (Watt) } \\
\boldsymbol{v} & =\text { Tengangan Operasional (Volt) } \\
\boldsymbol{t}_{\boldsymbol{d}} & =\text { Durasi Backup Daya (Hour) } \\
\boldsymbol{\eta} & =\text { Faktor Efisiensi (\%) }
\end{array}
$$

Sehingga kebutuhan rectifier dapat dirumuskan sebagai berikut,

$$
R=\left(L+\frac{B_{c}}{t_{c}} \times v_{c}\right) \times \frac{1}{\eta}
$$

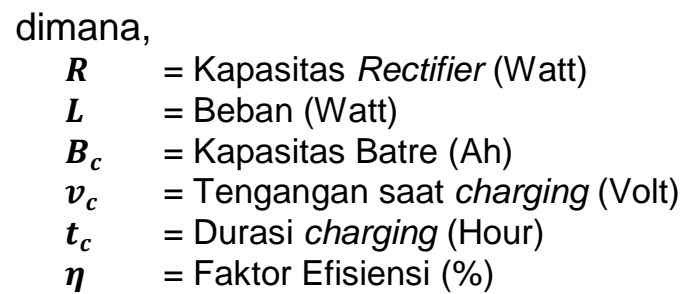

Trafik yang dapat dibawa oleh Base Station Tranceiver dapat diukur dengan formulasi erlang [1], dimana intensitas trafik sebanding dengan laju kedatangan panggilan (call rate) dan waktu pendudukan panggilan (holding time), atau dapat pula dilakukan dengan pendekatan yang merupakan hasil pendudukan dari seluruh kanal yang tersedia oleh Base Station Tranceiver dalam satu waktu perioda, sehingga dapat di rumuskan dengan formulasi berikut,

$$
A=\frac{1}{T} \times \sum_{n=0}^{N} t_{n}
$$

dimana,

$$
\boldsymbol{A} \quad=\text { Intensitas Trafik (Erl) }
$$




$$
\begin{array}{ll}
\boldsymbol{T} & =\text { Perioda Pengamatan (Jam) } \\
\boldsymbol{N} & =\text { Total Kanal Yang Tersedia } \\
\boldsymbol{t}_{\boldsymbol{n}} & =\text { Waktu Pendudukan (menit) }
\end{array}
$$

Secara umum pendudukan trafik memiliki pola seperti pada Gambar 2 [1], dimana intensitas trafik umumnya mulai naik pada pukul 7 dan mencapai puncak prioda busy hour pada rentang pukul 18 hingga pukul 23.

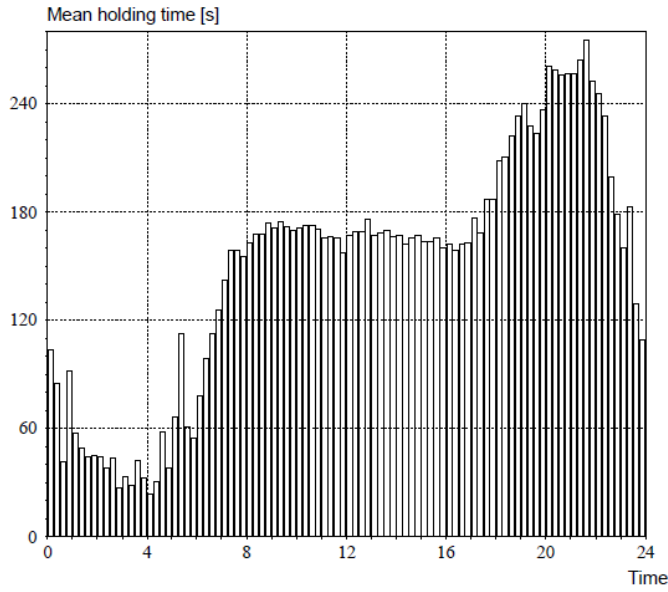

Gambar 2. Pola Umum Distribusi Trafik

Jika Base Station Tranceiver terletak pada wilayah-wilayah yang tergolong bad grid dengan tingkat pemadaman tinggi dan terjadi secara regular, maka hal ini akan berdampak pada terjadinya traffic loss, khususnya apabila Base Station Tranceiver tersebut kehilangan catuan utama pada perioda busy hour.

\section{METODOLOGI}

Dalam penelitian ini proses desain backup daya akan dianalisa menggunakan pendekatan tekno-ekononi [2],[3] dimana proses desain teknis akan divaluasi secara ekonomis sehingga hasil rancangan nantinya akan memberikan evaluasi kelayakan desain yang menyeluruh baik dari aspek teknis dan valuasi ekonomis.

Model analisa tekno-ekonomis yang akan digunakan pada penelitian ini dapat diilustrasikan sebagai Gambar 3 berikut.

Struktur biaya dalam desain ini dapat dibedakan menjadi dua kelompok besar yaitu Capital Expenditure (CAPEX) [5] \& Opeation Expenditure (OPEX) [6].

Terkait perhitungan CAPEX, diperlukan formulasi teknis melalui persamaan (1) dan (2) untuk menentukan kapasitas batre, rectifier dan material pendukung serta menyesuaikan dengan data spesifikasi perangkat yang digunakan [7],[8],[9].

Dalam perhitungan OPEX dilakukan analisa kebutuhan biaya untuk operasional, maintenance, sparepart, dan biaya lainnya [6].

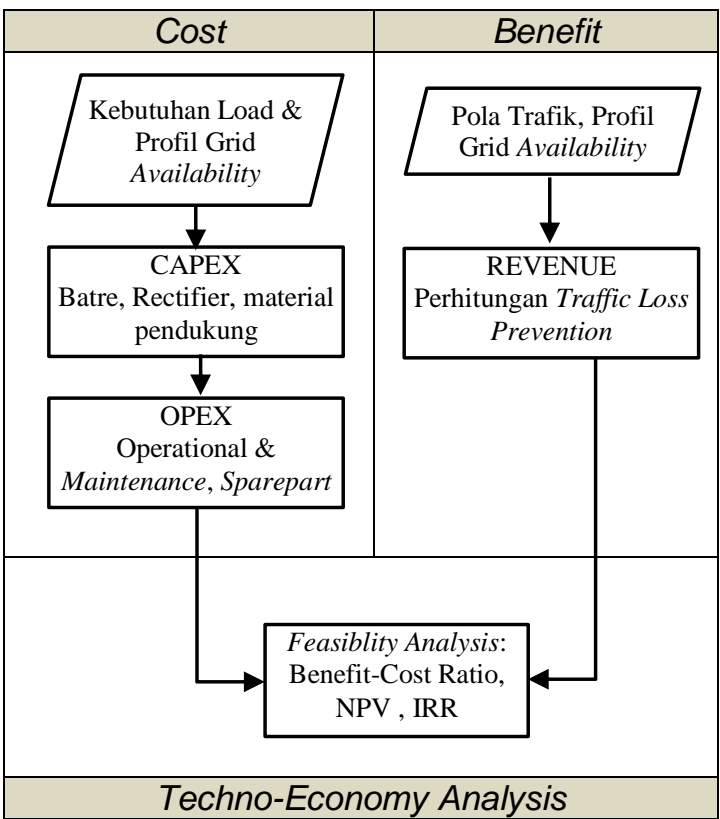

Gambar 3. Model Analisa Tekno-Ekonomi

Proses akhir dalam model analisis TeknoEkonomi adalah proses evaluasi feasibility, dimana beberapa parameter yang digunakan diantaranya adalah Net Present Value (NPV) dan Internal Rate of Return (IRR) [10].

\section{HASIL DAN PEMBAHASAN}

Pada penelitian ini model analisis berbasis tekno-ekonomi akan disimulasikan pada dua tipe Base Station Tranceiver yaitu tipikal beban $1500 \mathrm{~W}$ dan $3000 \mathrm{~W}$, dimana dalam simulasi ini digunakan beberapa parameter asumsi seperti yang tertera pada Table 1 berikut.

Tabel 1. Parameter Asumsi

\begin{tabular}{|l|c|}
\hline \multicolumn{1}{|c|}{ Items } & Value \\
\hline Tipikal Beban & $1500 \mathrm{~W}$ dan $3000 \mathrm{~W}$ \\
\hline Profil outage area bad grid & 10 hour/day \\
\hline Nominal Operation voltage & $48 \mathrm{v}$ \\
\hline Durasi charging & 5 hour \\
\hline Kapasitas Unit Batre & $48 \mathrm{v}-75 \mathrm{Ah}$ \\
\hline Kapasitas Unit Rectifier & $2000 \mathrm{~W} /$ Modul \\
\hline Hurdle Rate & $17 \%$ \\
\hline Annual Inflation & $5 \%$ \\
\hline
\end{tabular}




\begin{tabular}{|l|c|}
\hline Kurs USD & 13.500 IDR \\
\hline Rata-rata tarif per menit & 200 IDR \\
\hline Depresiasi & 5 Tahun \\
\hline
\end{tabular}

Mengacu kepada proses dan formulasi yang telah dibahas pada bagian metodologi didapatkan hasil kalkulasi kebutuhan teknis untuk sistem backup daya untuk dua jenis tipikal beban tersebut seperti yang terlihat pada Tabel 2 berikut,

Tabel 2. Kebutuhan Teknis Sistem Backup Daya

\begin{tabular}{|l|c|c|}
\hline \multicolumn{1}{|c|}{ Items } & $1500 \mathrm{~W}$ & $3000 \mathrm{~W}$ \\
\hline Battery (48v75Ah) & $375 \mathrm{Ah}$ & $675 \mathrm{Ah}$ \\
\hline Rectifier (2000Watt) & 6 Modul & 9 Modul \\
\hline $\begin{array}{l}\text { Others (Mechanical } \\
\text { \& Electrical Material) }\end{array}$ & $1 \mathrm{Lot}$ & $1 \mathrm{Lot}$ \\
\hline
\end{tabular}

Dengan beberapa parameter asumsi pada Tabel 1 dan hasil dimensioning kebutuhan teknis pada Tabel 2 maka dihasilkan NPV dan IRR sebagai berikut,

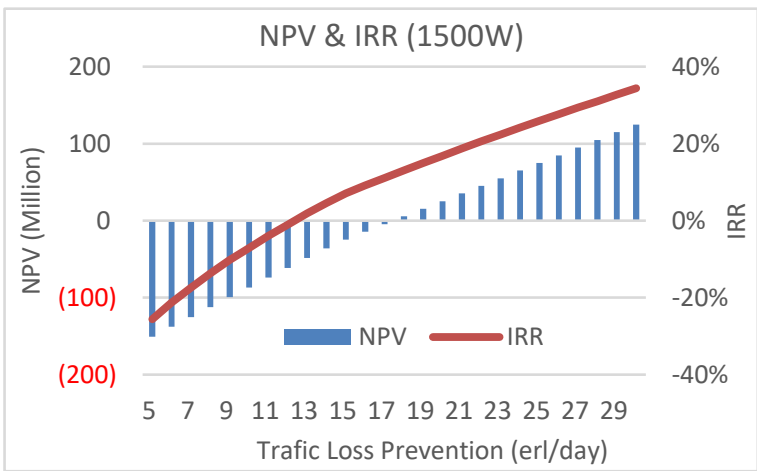

Gambar 4. NPV \& IRR (1500W)

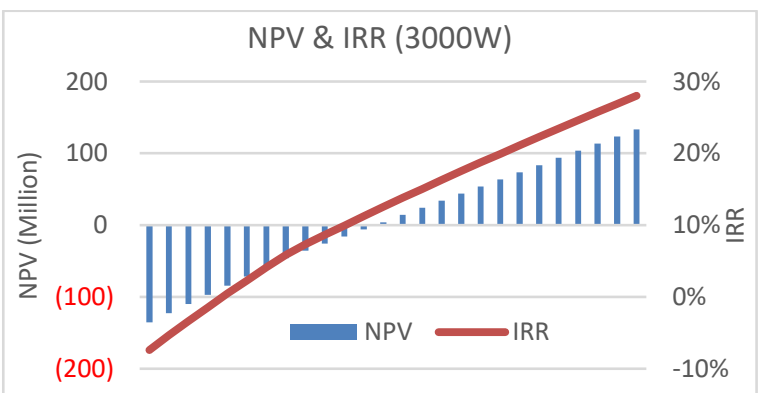

15171921232527293133353739

Trafic Loss Prevention (erl/day)

Gambar 5. NPV \& IRR (3000W)

Pada Gambar 4, terlihat bahwa dimensioning teknis (pada Tabel 2) feasible untuk diimplementasikan pada Base Station Tranceiver (dengan tipikal beban 1500W) yang memiliki potensi Traffic Loss Prevention diatas 21 erlang per hari, dimana dengan kondisi tersebut akan dihasilkan IRR diatas hurdle rate.

Sedangkan untuk tipikal 3000W seperti yang terlihat pada Gambar 5, maka dimensioning teknis (pada Tabel 2) feasible untuk diimplementasikan pada Base Station Tranceiver yang memiliki potensi Traffic Loss Prevention diatas 31 erlang per hari.

Apababila dimensioning teknis pada Tabel 2 diimplementasikan pada Base Station Tranceiver yang memiliki potensi Traffic Loss Prevention dibawah nilai yang telah disebutkan tersebut diatas, maka dimensioning teknis pada Tabel 2 tersebut menjadi tidak feasible untuk diimplementasikan (diperlukan adjustment kembali dari sisi dimensioning teknisnya).

Analisa selanjutnya adalah melihat sensitivitas beberapa parameter terhadap nilai NPV dan IRR seperti yang terlihat pada Gambar 6 dan Gambar 7 berikut,

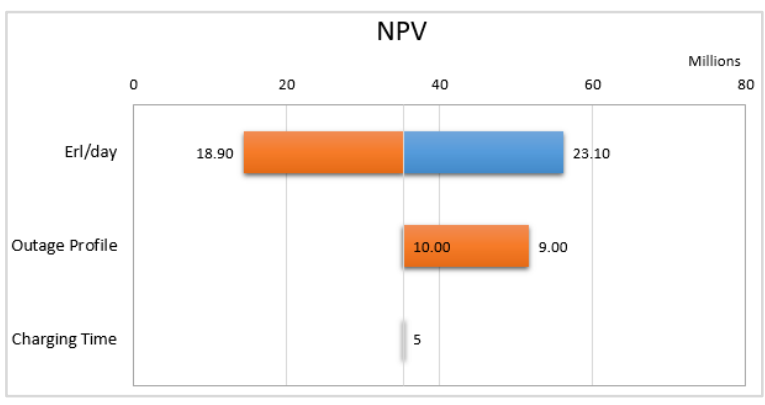

Gambar 6. Sensitivitas NPV

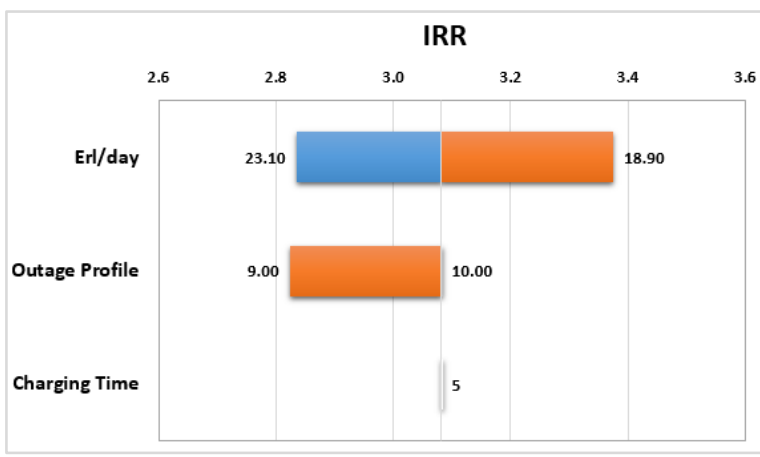

Gambar 7. Sensitivitas IRR

Pada Gambar 6 dan Gambar 7 terlihat bahwa evaluasi feasibility dengan tolok ukur NPV dan IRR memiliki sensitivitas yang cukup tinggi terhadap parameter potensi 
Traffic Loss Prevention dan Outage Profile dari catuan utama Base Station Tranceiver.

\section{KESIMPULAN}

Analisis tekno-ekonomi sistem backup daya pada Base Station Tranceiver yang telah dibahas diatas dapat memberi gambaran secara menyeluruh baik dari sisi aspek teknis maupun dari valuasi ekonominya. Dimensioning kebutuhan teknis akan membentuk faktor biaya sedangkan faktor benefit terbentuk dari besarnya potensi traffic loss prevention.

Atas kedua hal tersebut maka dapat dilakukan feasibility analisysis untuk menentukan dalam kondisi yang seperti apa dimensioning teknis tersebut feasible untuk diimplementasikan, dan dalam kondisi yang seperti apa re-dimensioning teknis harus kembali dilakukan agar desain sistem backup daya tersebut menjadi feasible baik dari sisi aspek teknis dan juga valuasi ekonominya.

\section{UCAPAN TERIMAKASIH}

$\begin{array}{ccc}\text { Terkait penelitian ini } & \text { penulis } \\ \text { mengucapkan terima kasih } & \text { kepada } \\ \text { beberapa pihak diataranya Civitas }\end{array}$ Akademika Universitas Pamulang (Program Studi Teknik Elektro), PT Telkominfa (Unit Energy Service Solution dan Unit Business Solution), serta pihak lainnya yang selama ini telah banyak membantu memberikan kontribusi ide dan saran dalam penelitian ini.

\section{DAFTAR PUSTAKA}

[1] Villy B. Iversen, "Teletraffic Engineering Handbook", Technical University of Denmark, 2001

[2] Ashutosh Jha, Debashis Saha, "Technoeconomic assessment of the potential for $L T E$

based 4 G mobile services in rural India", IEEE, 2015

[3] Miroslaw K, Krzysztof W, Bart L, Koen C, Sofie V, Mario P, Lena W, Jiajia C, Attila M, "General Framework for TechnoEconomic Analysis of Next Generation Access Networks", IEEE, 2010

[4] Fatuma Simba, Lena Trojer, Bakari M, Nerey M, Emmanuel M, "Technoeconomic Analysis of UMTS900 and
UMTS2100 for Rural Connectivity in Tanzania", IEEE, 2012

[5] Kosmas Tsilipanos, "Modeling Complex Telecom Investments: A System of Systems Approach", IEEE, 2015

[6] Donald G N, Ted G E, Jerome P L, "Engineering Economic Analysis", Oxford University Press, 2004

[7] _ "Flexi Multiradio BTS LTE Datasheet", NSN, 2013

[8] _ _ "Lithium Iron Phosphate Battery - Datasheet", Vision Group, 2017

[9] _ "Embedded Power System Datasheet", Huawei, 2016

[10] Leland Blank, Anthony Tarquin, "Engineering Economy", Mc Graw Hill, 2005

[11] Peter K, Stanislav M, Jindrich S, Jakub $\mathrm{V}$, "Techno-economic Analysis of Different Battery Storage suitable for Off-Grid Systems", IEEE, 2014

[12] P Medina, A W Bizuayehu, J P S Catalao, E M G Rodrigues, J Contreas, "Electrical Energy Storage Systems: Technologies' State-of-the-Art, Techno-Economic Benefits and Applications Analysis", IEEE, 2014 